\title{
LA BANCA MÓVIL COMO ALTERNATIVA PARA LA INCLUSIÓN SOCIAL EN ÁREAS RURALES
}

\author{
CARLOS A. AZABACHE
}

- Profesor de Investigación de Mercados

Dirección de Administración y Negocios Internacionales

Facultad de Negocios, UPC.

\begin{abstract}
RESUMEN
Esta investigación estudia la viabilidad de implementar la banca móvil en el Perú, especialmente en las áreas rurales. El trabajo se justifica porque en el país, la población de bajos niveles de ingresos tiene escaso acceso a los servicios bancarios formales, no sólo debido a la disparidad económica, sino también debido a brechas en los mercados de estos servicios. Esta investigación usa la experiencia de FITEL como fuente de datos y desarrolla un análisis empírico del que se infiere que la banca móvil en el país sí es viable y ayudaría a reducir las deficiencias antes aludidas.
\end{abstract}

Palabras clave: Banca móvil, servicios financieros en países rurales en vías de desarrollo, inclusión social, infraestructura de telecomunicaciones.

\begin{abstract}
This paper addresses mobile banking implementation viability in Peru, especially in rural areas. In Peru, people with low levels of income has scarce access to formal banking services, not only because of economic disparity, but also as a result of market gaps related to these services. This paper gathers data from FITEL projects, and develops an empirical analysis from which it can be concluded that mobile banking in Peru is possible and would help to reduce the aforementioned deficiencies.
\end{abstract}

Keywords: Mobile banking, financial services in developing rural countries, social inclusion, telecommunications infrastructure.

La telefonía móvil es un servicio muy importante dentro de la economía peruana, y ha estado creciendo rápidamente durante los últimos años. Según Osiptel ${ }^{1}$, en setiembre de 2009 la cantidad total de teléfonos móviles llegó a 23,5 millones en el país, con un 84\% de cobertura en cuanto a población.

El desarrollo de las telecomunicaciones en el Perú, como consecuencia de las TIC, se está convirtiendo en una meta

1. El regulador nacional del sector de telecomunicaciones. que, así como en el resto de países en la región, el Estado percibe como una prioridad. Como resultado de esto, ha implementado políticas de acceso universal (Decreto Supremo 020-98-MTC), las cuales, de modo local, se han centrado en las zonas rurales de menores ingresos. Estas soluciones, que se presentan como proyectos de telecomunicaciones, se basan en los enfoques market gap (brecha del mercado) y real gap (brecha real), que explican la limitación de la inversión privada para proporcionar conectividad a esas localidades.

Por otro lado, los Gobiernos de las economías emergentes también han estado implementando programas para alentar a los operadores a desplegar redes de telecomunicaciones, con el fin de reducir la brecha digital y contribuir a la integración económica de las áreas rurales con economía de mercado formal.

Además, el servicio de telefonía móvil se ha desarrollado como resultado del crecimiento natural de los otros servicios de telecomunicaciones, y de acuerdo con el cambio de tecnología para el uso de los contenidos. Esa es la situación de las localidades, donde, si bien todavía faltan redes de telefonía fija, ya se cuenta con redes móviles, debido a sus ventajas técnicas y económicas.

La solución de mercado real, por su parte, se considera un caso exitoso de disminución de la brecha real, al ofrecer con la telefonía móvil una alternativa para la comunicación entre los grupos de menores ingresos.

En el caso del Perú, las redes satelitales han estado contribuyendo a cubrir las limitaciones de acceso para los servicios de telecomunicaciones utilizando la política de acceso universal diseñada por el Estado y ejecutada por FITEL, fondo adscrito al Ministerio de Transportes y Comunicaciones (MTC).

La presente investigación considera la posibilidad de estudiar los usos complementarios entre el servicio de telefonía fija, la telefonía pública y el servicio móvil en lugares remotos, donde el sistema bancario aún es incipiente, empleando plataformas satelitales. Se basa en el análisis del desarrollo real de los servicios financieros móviles en todo el mundo, tomando en cuenta los casos más exitosos. El objetivo es analizar la posibilidad de implementar el servicio de banca móvil o el de pago móvil en zonas rurales del Perú, ya que en ellas aún no se cuenta con acceso al servicio financiero y bancario. 
Hoy en día, las empresas privadas ya comenzaron la expansión del mercado bancario utilizando el sistema satelital, que proporciona un terminal conectado a la red satelital. Este es el caso de los operadores de telecomunicaciones en zonas rurales que soportan internet.

La tendencia natural de esos nuevos mercados es hacia la expansión del servicio, ya que este proceso se inicia proporcionando el acceso a la conectividad. En adición al servicio de telefonía pública - en un inicio la única alternativa de comunicación-, los clientes demandan el servicio móvil. Este despliegue de la red móvil se autofinanciará, en la mayoría de los casos, organizando un acuerdo de cooperación denominado contrato público-privado entre el operador de telefonía móvil y el Gobierno regional.

Como consecuencia de ello, los servicios bancarios se pueden expandir a las áreas rurales mediante la banca móvil, como una herramienta para ofrecer servicios bancarios a las economías emergentes. En esta situación en particular, la banca móvil puede ayudar a integrar las localidades rurales a los servicios financieros, para lo que será necesario contar con el apoyo del Gobierno central, a través de subsidios a la demanda. Esta estrategia permitirá estimular la demanda de servicios y, a su vez, incentivará a los operadores privados a desplegar sus propias redes en estas áreas remotas.

Mariscal (2009) dijo en su investigación reciente, "Móviles para el desarrollo: $m$-banking":

Un ejemplo exitoso de una solución de mercado es el aumento dramático en teléfonos móviles que ha ofrecido la alternativa más rentable y accesible a las comunicaciones para grupos de bajos ingresos. Las estrategias comerciales innovadoras, como los sistemas de prepago, han contribuido a aumentar drásticamente la penetración de dispositivos móviles en los países en desarrollo. La exclusión financiera se ha convertido en una preocupación importante para muchos países en desarrollo, ya que refuerza la exclusión social ofreciendo estos servicios a grupos de bajos ingresos que tienen acceso a teléfonos móviles, pero no a los servicios financieros. (p. 2)

Aún más, debido al acceso a internet en años recientes, la telefonía móvil se está convirtiendo en el último recurso de provisión de servicios bancarios. Al proporcionar las aplicaciones interactivas, el sistema bancario puede suministrar a sus clientes un servicio de bajo costo en términos de infraestructura, mejorando las economías de red. Esta propuesta de investigación se basa en la importancia del desarrollo de una banca móvil como herramienta social para brindar los servicios, valiéndose también de instrumentos sociales como mecanismos de inducción, ya sea por medio de subsidios o empleando las redes comerciales que ofrecen servicios bancarios por punto de servicio (POS).
Se propone estudiar la posibilidad de innovar en el sector bancario en áreas rurales utilizando la infraestructura de telefonía móvil en el Perú, ya que su penetración es más alta que la bancaria. El enunciado del problema es el siguiente: “La baja penetración de la banca en áreas rurales en el Perú y el bajo nivel de servicio resultante pueden mejorarse con los servicios de telecomunicaciones".

El objetivo general de esta investigación es identificar las posibilidades de expansión del sistema bancario en área rurales utilizando la red móvil en estas zonas del Perú. Los objetivos específicos, por su parte, son los siguientes: i) determinar la situación real de las TIC para facilitar el uso de la banca móvil en zonas rurales en el Perú, ii) identificar las reducciones de eficiencias y costos en los servicios bancarios para las localidades rurales y iii) brindar recomendaciones para las políticas públicas necesarias para facilitar el uso de las TIC para aplicaciones bancarias en el servicio de telefonía móvil.

\section{METODOLOGíA}

Utilizaremos el método hipotético deductivo, respaldado por la teoría del desarrollo económico y las investigaciones y experiencias disponibles en telecomunicaciones, como las relacionadas con los proyectos de Fitel, el Banco Mundial y la Unión Internacional de Telecomunicaciones (UIT), además de datos secundarios. La hipótesis es la siguiente: "La banca móvil es una forma factible de extender el sector bancario en zonas rurales en el Perú".

\section{Marco Teórico}

Desde un punto de vista económico, y según Adam Smith y David Ricardo, el desarrollo es una consecuencia natural de la expansión del mercado (Failache, 2016). Pero también es importante considerar que esta consecuencia es válida en un mercado competitivo, es decir, uno sin fallas.

En el caso que nos ocupa, podríamos identificar como fallas las siguientes restricciones:

- Distribución desigual de la riqueza.

- El sistema de fijación de precios del mercado no es eficiente para asignar la salida.

- Pocos competidores y precios altos.

Esas fallas del mercado restringen el acceso de los consumidores a los bienes y servicios necesarios para sus requerimientos básicos. En ese caso, el Estado juega un papel fundamental en la "administración de los mismos", aumentando la competencia mediante su fomento, y el tamaño del mercado a través de la regulación económica. 
Usualmente, esas fallas de mercado permanecen en el caso de los servicios públicos, incluida la telefonía fija, que anteriormente era una empresa pública, un monopolio natural como en muchos otros países. Actualmente, a pesar de la privatización, continúa como un operador dominante.

Para proteger y maximizar el bienestar del consumidor es que se creó OSIPTEL, la oficina gubernamental reguladora, además de FITEL, para promover el despliegue de las líneas de telefonía de red fija y aumentar la conectividad a las áreas rurales, las cuales, en el Perú, han estado sufriendo la falta de despliegue de infraestructura de telecomunicaciones, y tradicionalmente han sido asociadas con programas de inversión de envergadura emprendidos por entidades grandes (operadores de telecomunicaciones y agencias gubernamentales como FITEL). Esto se explica por el hecho de que solo estas entidades fueron capaces de disponer del capital necesario a fin de alcanzar las economías de escala necesarias para establecer estas redes.

Incluso hoy en día, el progreso tecnológico ha proporcionado comunicaciones inalámbricas y reducciones de costos unitarios en componentes básicos, dando como resultado ganancias significativas en la penetración de telefonía básica entre los países en desarrollo.

Galperin (2005) comenta que "se ha producido un proceso similar con respecto a la entrega de servicios de acceso a internet. Hoy en día, el nivel de conectividad a internet en el mundo en desarrollo no solo está muy por debajo del de las naciones desarrolladas, sino que también está muy concentrado en áreas urbanas de riqueza" (Banco Mundial, 2004)

Los enfoques de market gap y real gap se muestran en el siguiente gráfico:

\section{Gráfico 1. The market real gap}
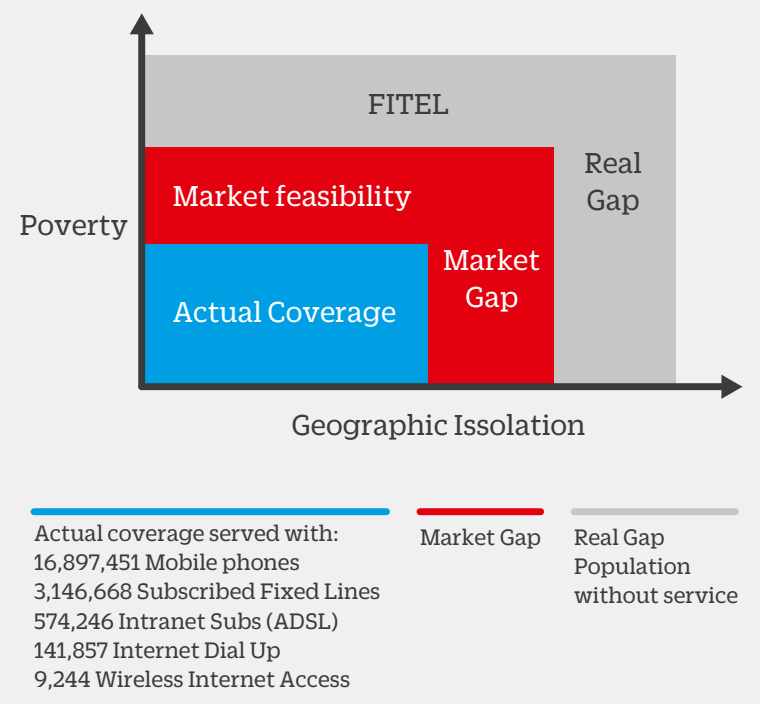

Fuente: Banco Interamericano de Desarrollo (2008).

En el gráfico 1 se aprecia el enfoque de brechas. El real gap es la brecha real de infraestructura, y se presenta como la primera dificultad en la expansión de los mercados. En este aspecto, corresponde a las políticas públicas reducir esta dificultad, desarrollando proyectos de infraestructura a través de FITEL.

También se muestra el market gap, brecha de mercado en las localidades rurales como consecuencia de las fallas en el sistema de fijación de precios; es decir, los precios o tarifas de los servicios de telecomunicaciones son mayores de lo que el cliente está dispuesto a pagar.

Galperin (2005) dijo:

Lograr que los residentes rurales vivan fuera de la pobreza es una empresa compleja que implica una variedad de estrategias de desarrollo, todo lo cual presupone un mejor acceso a las TIC . En primer lugar, varios estudios han demostrado que las TIC mejoran la productividad de los pobres de las zonas rurales, al reducir los costos de transacción y optimizar los flujos de información en productos agrícolas y mercados de factores, incluyendo crédito y datos relevantes para actividades agrícolas (Torero, 2000; Eggleston, et al. 2002). Segundo, la realidad de las comunidades rurales en América Latina es que dependen cada vez más de actividades no agrícolas, y atraer estas actividades requiere de enlaces de comunicación confiables a los centros urbanos y de una fuerza de trabajo más educada, la cual exige un mejor acceso a los servicios de TIC (De Janvry y Sandoulet, 2000). Además, la administración y la prestación de servicios gubernamentales -en particular, de programas de asistencia social para los pobres de las zonas rurales- se pueden mejorar de manera espectacular mediante el uso de las TIC. "Finalmente, el acceso mejorado genera empoderamiento local, un factor importante para la sostenibilidad de las estrategias de desarrollo rural (Heeks, 2001)". (p. 5)

En cuanto al Perú, algunos proyectos financiados por FITEL se han optimizado y han brindado conectividad a las áreas rurales, llenando la brecha del mercado, e incluso, en la mayoría de los casos, la brecha real. La diferencia entre la brecha del mercado y la real estriba en el acceso a la infraestructura, que es la principal preocupación para el Estado. Contar con infraestructura permitirá alentar a los operadores privados a desplegar y expandir sus redes y cobertura.

Los proyectos de FITEL se han desarrollado dentro de este enfoque. Algunos de ellos están totalmente cubiertos por el subsidio: los llamados proyectos de telecomunicaciones; y otros lo están parcialmente: los proyectos piloto. La tecnología utilizada para implementar el proyecto es de libre elección por parte del operador.

Posteriormente, una vez que el proyecto se implementa, incluyendo la capacitación de la población para el uso de los servicios (telefonía pública e internet), será posible que el mercado se expanda en forma natural, como es el caso de la llegada de nuevos operadores privados. Es así que, en los proyectos FITEL, luego de cierto tiempo de operación aparece el operador privado (competencia) en el mercado, 
en una evolución mercantil que implica una evolución de la sociedad, porque promueve la integración social de estas localidades con el resto del país.

También es importante considerar que se podrán ofrecer otras aplicaciones; por ejemplo, el servicio de voz IP, utilizando las aplicaciones de internet. Más aún, en la actualidad existe la posibilidad de servicios de voz y datos empleando la misma infraestructura; es el caso de las tecnologías WLAN.

El Estado peruano, a través de FITEL, ha financiado la expansión de la red de operadores privados, subsidiando las posibles pérdidas económicas en el despliegue de infraestructura en las áreas rurales. En algunos países, como Chile y Colombia, también se ha utilizado la política de acceso universal para financiar proyectos denominados telecentros en áreas rurales. Dichos centros son cabinas públicas que proporcionan los servicios de telefonía y acceso a internet en las zonas rurales.

Para brindar ayuda a las personas que viven en la pobreza rural, se ha implementado un nuevo enfoque en la estrategia del Estado peruano, el cual consiste en ofrecer subsidios directamente a la demanda. La razón para hacer esto es que en el enfoque de la brecha del mercado se considera que, incluso cuando se despliega la infraestructura, la pobreza no permite al consumidor utilizar estos servicios de manera adecuada.

Esta política fue iniciada durante el gobierno de Alejandro Toledo mediante el programa Juntos, cuyo objetivo es ayudar a las personas en situación de extrema pobreza, riesgo y exclusión con el suministro de los servicios básicos de nutrición, salud, educación e identidad social. Comenzó en setiembre de 2005, y para enero de 2009 ya había registrado 420491 hogares que vivían en extrema pobreza en 638 distritos rurales, distribuidos en 14 regiones de todo el país. El programa, operativamente, realiza transferencias de dinero por un monto fijo de S/100, equivalente a US\$34. La restricción natural que enfrentan estos tipos de programas es principalmente la de supervisión y distribución desde su implementación, y, luego, la de control.

La selección de los distritos para el programa toma en cuenta estas variables: violencia sufrida, pobreza extrema, pobreza por necesidades básicas insatisfechas, brecha de pobreza y falta constante de nutrición en la infancia. Debido a la importancia de este programa para combatir la pobreza, vale indicar que ha recibido el reconocimiento de Unicef y del PNUD.

El mecanismo para asignar el dinero a la población es a través del sistema bancario, después de la identificación de las personas objetivo. Y esto es lo relevante en el caso que nos ocupa, porque el propósito de este documento es respaldar la idea de que los proyectos de telecomunicaciones proporcionados por FITEL pueden ayudar a promover el sistema bancario en áreas rurales, usando los servicios de comunicación y, en especial, el de telefonía móvil.

En este sentido, mientras que la exclusión digital está siendo abordada por teléfonos móviles, la exclusión financiera, la incapacidad de acceder al sistema bancario, sigue siendo un problema fundamental, no solo por la dificultad de proporcionar los servicios bancarios, sino también por la falta de poder adquisitivo, lo cual motiva la creación de programas de ayuda del Estado, otorgando subsidios para las áreas rurales.

En consecuencia, los programas sociales deben promover el desarrollo del sistema bancario, y la banca móvil puede ser una herramienta útil, incluso para introducir ayuda financiera en las áreas rurales. Por otro lado, diversos estudios identifican un impacto positivo de los móviles sobre la eficiencia productiva en los países en desarrollo (Thompson \& Garbacz, 2007; como se citó en Mariscal, 2009).

\section{Impacto del Servicio de Banca Móvil}

Recientemente, ha aumentado el interés académico por comprender las causas y los impactos en cuanto al uso de la telefonía móvil en los países en desarrollo. Desde la perspectiva de la oferta, se ha descubierto que el sistema prepago ha contribuido significativamente a la expansión móvil en estos países (Hodge, 2005; Mariscal \& Bonnia, 2006; Stork, Esselaar \& Ndiwalana, 2006; como se citó en Mariscal, 2009). En el este de África, por ejemplo, la banca móvil se está convirtiendo en un gran negocio de rápido crecimiento, debido a su capacidad innovadora para proporcionar servicios bancarios a la población que solo tiene acceso limitado a los servicios bancarios formales; en ese caso, permite el incremento en la intermediación financiera, especialmente para las áreas rurales. El nuevo mercado está abierto, y muchos operadores móviles están encontrando el mercado rentable de "bajo valor, alto volumen" en toda África.

La variable más importante para este crecimiento es la competencia, y las agencias reguladoras pueden ayudar a este propósito. En términos de impacto de la difusión móvil, los estudios en TIC buscan identificar cómo los móviles pueden contribuir al crecimiento económico y a la reducción de la pobreza. Por ejemplo, el estudio de Jensen (2007) sobre el mercado pesquero en Kerala (India), con una investigación de seis años en tres distritos, encuentra un impacto significativo en el acceso a la información de oportunidades de negocio en estos mercados poco desarrollados. El acceso a información a través de los teléfonos móviles redujo la dispersión de los precios y el desperdicio, y produjo el aumento de las ganancias de los pescadores y el bienestar del consumidor. Desde el punto de vista social, el impacto de las TIC, la telefonía móvil proporciona fuertes vínculos con familiares y amigos cercanos, mientras que los vínculos débiles con otros, como empresarios, docentes o médicos, brindan información y posibles oportunidades económicas y sociales (Goodman, 2005, p. 63; como se citó en Mariscal, 2009).

En el caso de América Latina, aún se necesita el desarrollo del servicio móvil como una herramienta para brindar otros servicios que ayuden a combatir la pobreza. Las teorías de los avances modernos identifican el mercado financiero como una parte esencial del proceso de desarrollo. En mercados medianos y grandes, el desarrollo financiero fomenta las inversiones de capital, la entrada de nuevas 
empresas al mercado y la innovación, todo lo cual genera crecimiento económico.

Esto es posible en el marco del mercado en que la población puede calificar para un crédito, pero en las economías emergentes, como se mencionó anteriormente, algunas fallas de mercado crean distorsiones y limitaciones para el sistema bancario. "La tecnología de hoy ha cambiado el panorama para la inclusión financiera; ha permitido a los nuevos participantes en el sistema bancario ofrecer costos más bajos y la posibilidad de acceso ubicuo al servicio bancario" (Mariscal, 2009, p.9)

En la mayoría de los casos, la banca móvil proporciona la aplicación que utiliza la telefonía o un dispositivo diferente como punto de venta para realizar transacciones financieras, tales como el almacenamiento de valor en una cuenta a través del teléfono, la capacidad de convertir en efectivo el valor almacenado en una cuenta y la facultad de transferir el valor almacenado entre cuentas (Donner, 2007; como se citó en Mariscal, 2009).

Incluso para las situaciones en que el valor almacenado no puede de ser utilizado en el momento, los usuarios han creado estrategias como el intercambio de minutos, por ejemplo, que se administran de modo similar a la moneda. Adicionalmente, se implementan otras soluciones; por ejemplo, cargar los costos de las transacciones a la facturación del teléfono móvil, en la medida en que cuenten con un plan pospago.

En general, la banca móvil brinda la posibilidad de derribar barreras importantes para la inclusión financiera de los pobres: asequibilidad y disponibilidad física. En comparación con los bancos tradicionales basados en sucursales, la banca móvil tiene la ventaja de que no incurre en el costo de implementación, y, además, maneja costos menores para las transacciones de bajo valor y proporciona un enlace con el nuevo nicho de mercado: las personas que no están bancarizadas.

Al mejorar el uso de la infraestructura móvil existente y al ofrecer todos los servicios en línea, la banca móvil puede brindar eficiencia en los costos para la prestación de servicios de entrada y salida de efectivo. A nivel macroeconómico, la banca móvil está ayudando al crecimiento de las pequeñas empresas, impulsando la actividad económica. (Mariscal, 2009).

Esta situación está ocurriendo con los bancos centrales de Uganda, Tanzania y Kenia, que cuentan con un servicio de transferencia de dinero internacional regional a través de su servicio de roaming gratuito One Network; el dinero móvil es parte del comercio a pequeña escala en el este de África, revela Zain, uno de los nuevos operadores en Kuwait.

Como se puede observar en la tabla 1, existe una falta de acceso a los servicios financieros básicos en los países de América Latina. En el caso de la disponibilidad de cajeros automáticos (ATM), es posible verificar que, en la mayoría de los países de América Latina, este es un factor limitante para acceder a los servicios financieros.
Tabla 1. Sucursales y disponibilidad de ATM

\begin{tabular}{|l|r|r|r|r|}
\hline & $\begin{array}{c}\text { Geographic } \\
\text { branch } \\
\text { penetration }\end{array}$ & $\begin{array}{c}\text { Demographic } \\
\text { branch } \\
\text { penetration }\end{array}$ & $\begin{array}{r}\text { Geographic } \\
\text { ATM branch } \\
\text { penetration }\end{array}$ & $\begin{array}{c}\text { Demographic } \\
\text { branch } \\
\text { penetration }\end{array}$ \\
\hline Argentina & 1,4 & 10,01 & 2,09 & 14,91 \\
\hline Bolivia & 0,13 & 1,53 & 0,4 & 4,8 \\
\hline Brazil & 3,05 & 14,59 & 3,72 & 17,82 \\
\hline Chile & 1,98 & 9,39 & 5,06 & 24,03 \\
\hline Colombia & 3,74 & 8,74 & 4,1 & 9,6 \\
\hline Dominican & 10,83 & 6 & 27,24 & 15,08 \\
\hline Rep. & 4,38 & 9,3 & 2,97 & 6,32 \\
\hline Ecuador & 14,58 & 4,62 & 34,89 & 11,07 \\
\hline El Salvador & 11,49 & 10,12 & 22,93 & 20,2 \\
\hline Guatemala & 0,46 & 0,73 & 2,22 & 3,56 \\
\hline Honduras & 4,09 & 7,63 & 8,91 & 16,63 \\
\hline Mexico & 1,29 & 2,85 & 1,18 & 2,61 \\
\hline Nicaragua & 0,89 & 4,37 & 1,24 & 5,85 \\
\hline Perú & 1,28 & 4,41 & 4,81 & 16,6 \\
\hline Venezuela & & & & \\
\hline & & 6 & & \\
\hline & & & & \\
\hline
\end{tabular}

Fuente: Banco Mundial (2008).

Nota: la penetración de la sucursal geográfica se refiere al número de sucursales por 1000 kilómetros cuadrados; y la penetración de la rama demográfica, al número de sucursales por cada 100000 personas.

La disponibilidad de estas soluciones para la banca en áreas rurales depende de su capacidad para integrarse en la vida económica de los consumidores (Jenkins, 2008; como se citó en Mariscal, 2009).

Si consideramos nuestro mundo globalizado, las remesas y los pagos remotos constituyen un mercado muy grande e importante para usar el dinero móvil. La evidencia empírica refleja que los flujos mundiales de remesas llegaron a cerca de US\$318 000 millones en 2007. América Latina recibió remesas de US\$ 65000 millones en 2008, según el Banco Interamericano de Desarrollo (BID). La principal preocupación es que la gran mayoría de la población de estos países no tiene una cuenta bancaria; así, esta solución puede ayudar a las personas a utilizar el sistema financiero a bajo costo. El rol de los Gobiernos para cubrir el vacío de la brecha digital en América Latina es incentivar el uso de los puntos de acceso compartido, lo que significa la implementación de proyectos que brindan acceso a internet a las áreas rurales, prestando los servicios de telefonía e internet a las personas a través de un proveedor local del servicio, conocido en algunos países como telecentro. En el Perú, FITEL ha proporcionado recursos para mejorar los servicios en áreas rurales y ayudar a las personas. Sin embargo, el impacto de estos puntos de conexión ha sido limitado. No es suficiente proveer los recursos para que los operadores privados ofrezcan el servicio, sino que es necesario desarrollar el marco regulatorio. A pesar de este hecho, los programas de acceso universal en América Latina se enfocan, como se explicó anteriormente, en que las TIC puedan acceder a las brechas y cerrarlas. 
Tabla 2. Importancia de las remesas para América Latina

\begin{tabular}{|c|c|c|c|c|c|}
\hline & Remittances \% of GDP & $\begin{array}{l}\text { Remittances \% of } \\
\text { total income }\end{array}$ & $\begin{array}{l}\text { Households receiving } \\
\text { remittances (\%) }\end{array}$ & $\begin{array}{c}\text { Remittances through } \\
\text { Banks (\%) }\end{array}$ & $\begin{array}{c}\text { Remittances recipients w/ } \\
\text { bank account (\%) }\end{array}$ \\
\hline Bolivia & 8,7 & 1,14 & 3,26 & 50,9 & 44 \\
\hline Dominican Rep. & 9 & 10,31 & 17,88 & 40,2 & 66 \\
\hline Ecuador & 7,8 & 0,65 & 2,46 & 57,6 & 46 \\
\hline El Salvador & 18,2 & 11,57 & 22,52 & 78,6 & 31 \\
\hline Guatemala & 10,1 & 6,06 & 11,49 & 67,8 & 41 \\
\hline Honduras & 24,8 & 6,43 & 14,33 & 81,8 & 34 \\
\hline Jamaica & 18,3 & 13,63 & 20,9 & 19,2 & 65 \\
\hline Mexico & 2,9 & 2,79 & 4,72 & 70,2 & 29 \\
\hline Nicaragua & 14,9 & 5,59 & 18,62 & 40,7 & 10 \\
\hline
\end{tabular}

Fuente: Banco Interamericano de Desarrollo (2008).

La tabla 2 muestra, para 2008, que México es el receptor líder, con US\$24 millones correspondientes al 2,9\% del producto bruto interno (PBI), mientras que, para países como Guatemala, El Salvador, Honduras y Nicaragua, las remesas representan más del 10\% de su PBI.

Como se ha visto en la tabla 2, existe un segmento del mercado importante para las remesas en las economías en desarrollo que no tienen acceso al sistema bancario. Otro aspecto relevante es el alto costo que deben pagar las remesas enviadas a través de los canales formales, que llevan a muchos remitentes de remesas a agencias informales. La consultora Gamos (2006) estima que los sistemas de pagos basados en transferencias electrónicas de fondos en lugar de cheques pueden reducir hasta en $12 \%$ los costos y recibir remesas mediante el sistema bancario formal del mercado financiero. Asimismo, permiten acceder a otros servicios financieros, tales como las cuentas de ahorro. (como se citó en Mariscal, 2009).

El modelo que se presenta y estima en esta investigación sigue los resultados de un cuestionario aplicado a un grupo específico en áreas rurales llamado "Agricultores de la junta de regantes del valle del río Huaral", con sede en Lima, Perú. Se trata de seguir el razonamiento de la brecha del mercado mencionada por el Banco Mundial, en términos de las influencias del desarrollo de las TIC en la población y la inclusión financiera de los servicios móviles. Continuando con el ejemplo de Kenia, este documento de investigación intentará establecer una relación que respaldó la idea de que las TIC y los servicios móviles pueden adoptarse para generar un impacto positivo en la sociedad.

En esa línea de trabajo, una de las principales dificultades para lograr nuestros objetivos es la importancia del alto nivel de dispersión entre los usuarios de TIC en las zonas rurales. El impacto para la población del acceso a internet puede variar en términos de edad y conocimiento. Luego, la selección de la muestra se ha efectuado de forma aleatoria y supone una distribución igual de capacidades entre personas; de lo contrario, podría haber sido parcial.
Las principales limitaciones de esta investigación han sido el tiempo y el presupuesto para realizar una encuesta en el Perú, ya que las entrevistas personales podrían proporcionar una muestra más amplia de la población, dado que el acceso de las personas en las áreas rurales a través de internet siempre es limitado. No obstante, la investigación está considerando una muestra representativa del universo de usuarios de TIC en áreas rurales.

Al margen de las limitaciones, la principal pregunta de investigación está relacionada con el objetivo, que es descubrir los determinantes de la adopción de la banca móvil considerando su impacto potencial en términos de inclusión financiera y social. La pregunta de investigación general se ha formulado en términos de las posibilidades de la implementación del sistema de banca móvil en áreas rurales en el Perú. Por otro lado, la pregunta de investigación específica ha sido definida como un grupo de interrogantes: ¿cuál es la viabilidad del uso de las TIC en las áreas rurales como una forma de expandir la banca móvil en el Perú? ¿Cuáles son los factores que limitan su implementación utilizando las experiencias de los países latinoamericanos? ¿Cuáles son las recomendaciones para las políticas públicas necesarias para facilitar el uso de las TIC para aplicaciones bancarias en la banca móvil en localidades rurales?

La presente investigación responderá a estas preguntas siempre que la revisión de la literatura, los cuestionarios y las entrevistas a los expertos proporcionen información suficiente para resolverlos.

\section{La Metodología de Investigación}

La muestra fue seleccionada de la población de Lima, la capital del Perú, para el área urbana y del Proyecto Rural de Acceso a Internet, un proyecto de telecomunicaciones promovido por FITEL en 2008, que subsidió la instalación de 68 accesos a internet para cabinas públicas como modelo de negocios en la región de los Andes.

El análisis se basará en una regresión lineal respaldada por un modelo de lógica de regresión logística siguiendo el Modelo de Aceptación de Tecnología (TAM). 
La variable dependiente en este modelo será la aceptación del servicio de banca móvil para transferir dinero en lugar de hacer una transacción bancaria tradicional, lo que implica un modelo disruptivo para las personas no bancarizadas. La variable independiente podría ser cualquiera de los factores que pudiesen influir para tomar la decisión de usar el servicio de banca móvil, como el tiempo, la distancia y el gasto para el transporte, el costo de oportunidad del tiempo, los salarios y el acceso a internet.

Los resultados tratarán de poner a prueba las proposiciones relacionadas con la contribución de la banca móvil para aumentar la inclusión social en las zonas rurales del Perú. También se intentará responder a las preguntas de investigación definidas como las posibilidades reales de implementar el sistema de banca móvil en zonas rurales y cómo las evoluciones de los servicios móviles en el Perú pueden contribuir a la inclusión social a través de la inclusión financiera.

Para el análisis de la información se aplicará el modelo econométrico de logit, y también un análisis estadístico descriptivo de las variables socioeconómicas vinculadas a las condiciones de vida de la población del grupo de muestra y a cómo la banca móvil podría influir de manera positiva.

La metodología que se aplicará será hipotética-deductiva. Ello significa que el uso del marco teórico obtenido de la teoría económica y sus aplicaciones en los documentos de investigación de ICTD² será deductivo con un enfoque general sobre nuestra principal pregunta de investigación. Mediante el análisis de los cuestionarios y los datos, se aplicará un modelo logit econométrico, generalmente utilizado para datos discretos, con el fin de validar la disposición del uso de la banca móvil después de haber utilizado el acceso a internet.

\section{Modelos de Probabilidad no Lineal}

Llamados también modelos de elección cualitativa, intentan definir la probabilidad de un resultado como consecuencia de una situación determinada.

El modelo logit es uno de ellos, y se basa en la función de probabilidad logística acumulativa especificada, como lo siguiente:

$$
\begin{aligned}
& P_{i}=F\left(Z_{i}\right)=F\left(\alpha+\beta X_{i}\right)=\frac{1}{1+e^{-z i}}=\frac{1}{1+e^{-(\alpha+\beta x i)}} \\
& Z_{i}=\log \frac{P_{i}}{1+P_{i}}=\alpha+\beta x_{i}
\end{aligned}
$$

Esto significa que la variable dependiente en la ecuación de regresión es el logaritmo de la probabilidad de que la elección o el evento particular hará u ocurrirá, transformando el problema de predecir probabilidades dentro del intervalo $(0,1)$ al problema de predecir las probabilidades del evento dentro del rango de la línea real.

También es relevante considerar la interpretación de los resultados de este modelo. Como se mencionó anteriormente, el modelo logit debe interpretarse en términos de probabilidades: se usa para medir la

2. Information and communication technologies and development probabilidad de que ocurra algún evento $Y_{i}=1$. En términos de interpretación de los parámetros estimados, el modelo logit ofrece una señal en sus parámetros relacionada con la dirección de la probabilidad cuando el valor de la variable dependiente aumenta, pero el monto de la variación no proporciona la cantidad de la variación de la probabilidad.

En este caso, la relación entre las variables y la probabilidad de ocurrencia del evento esperado en el modelo logit no es lineal.

Los cuestionarios aplicados a la población en el valle de Huaral serán analizados por este modelo, y los resultados serán confrontados con las entrevistas a expertos y usuarios de servicios móviles, para estudiar el grado de aceptación del servicio de banca móvil antes de su implementación.

\section{Instrumento y Fuente de Recolección de Datos}

Los cuestionarios se aplicarán a una muestra transversal para 2010 en la región de Lima, debido a la proximidad con la ciudad capital, y tomando en consideración el factor común de la influencia del tamaño del mercado y sus efectos dinámicos. El análisis contará con el respaldo de datos cualitativos y cuantitativos asociados a la influencia y a la disposición del uso del servicio móvil para la inclusión financiera a través del servicio de banca móvil. Mediante el análisis estadístico de las respuestas, se presentará un modelo descriptivo y explicativo para conocer el objetivo principal de la presente investigación.

El análisis estadístico también comprenderá la posibilidad de aplicar técnicas cuantitativas como Turnbull, generalmente utilizada para cuestionarios con valoración contingente de una variable no paramétrica, que incluye respuesta cerrada para la disposición de usar y pagar por un servicio específico. Las preguntas consideradas en la encuesta se pueden clasificar en tres categorías o grupos. El primer grupo está relacionado con el comportamiento del consumidor en cuanto al servicio bancario tradicional y al costo transaccional al que puede tener que incurrir para usar esos servicios; el segundo grupo, con la asequibilidad de estos servicios frente al servicio de banca por internet; y el tercer grupo, con la economía de los usuarios en términos de relación social con los otros miembros de la familia, inclusión social, condiciones de vida, salarios, etcétera. La cantidad total de observaciones es de alrededor de 94 cuestionarios, y su análisis se explicará en detalle en la sección de análisis de datos.

La evaluación de impacto para los proyectos FITEL fue realizada por el impacto de las políticas gubernamentales para desarrollar las condiciones requeridas para la expansión de la red de telecomunicaciones como un medio para la inclusión social, pues el principal objetivo de esta investigación es promover la adopción de la banca móvil como parte de la política de acceso/servicio universal para el sector de telecomunicaciones en el Perú.

La información para las preferencias de los usuarios de servicios móviles se ha estructurado a partir de una muestra de 98 usuarios del valle de Huaral que recibieron el acceso a internet como parte del proyecto FITEL. 
Siguiendo el enfoque de Camner, Pulver y Sjoblom (2009), el objetivo de esta encuesta es encontrar la relación entre el sistema bancario y las personas no bancarizadas que pueden usar banca móvil / servicios de pago como un servicio de transformación.

Las condiciones del mercado en términos de la estructura de este, así como la asequibilidad de la demanda, son similares en África y en América Latina en términos generales, con una proporción considerable de la población en condiciones de pobreza de exclusión financiera y social.

El marco teórico detrás del cuestionario aplicado para las áreas rurales en el Perú sigue el principio del modelo de aceptación de tecnología (TAM), y también se menciona en la revisión de la literatura de la presente investigación.

La principal proposición detrás es que el servicio móvil puede constituir el medio para la digitalización del dinero, transformando el concepto del servicio bancario y llevando a las personas al sector formal. Algunas preguntas se refieren al servicio monetario de remesas como una disposición de usar el servicio móvil para transferir dinero de áreas urbanas a áreas rurales, 0 viceversa. El gráfico 2 representa el concepto de la interrelación en un enfoque de matriz con el uso de la banca móvil en comparación con el enfoque tradicional del servicio bancario. El punto clave está relacionado con la forma en que los usuarios perciben el servicio y lo fácil que puede ser para ellos en términos de asequibilidad y equilibrio de beneficios y costos.

\section{Gráfico 2. Comparación entre enfoques tradicional y} transformacional

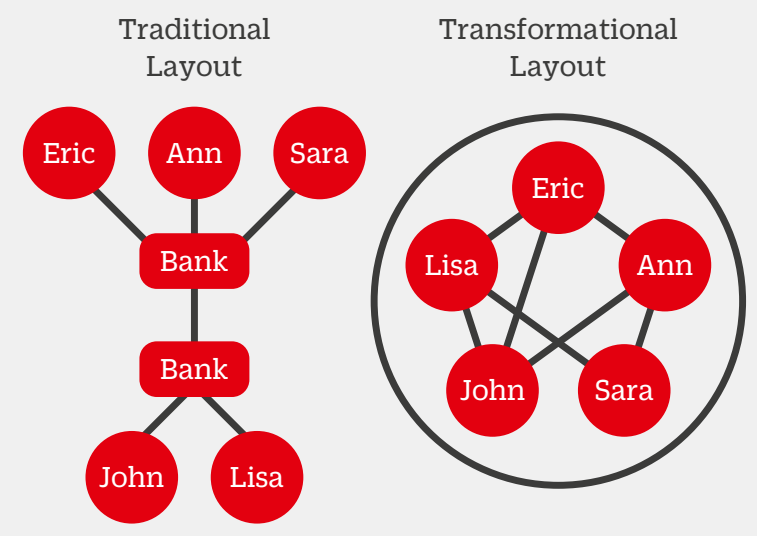

Fuente: Camner, Pulver, \& Sjoblom (2009).

Como se mencionó anteriormente, las preguntas se clasificaron en tres grupos: primero, las vinculadas a las características del servicio bancario y si son usuarios de servicios bancarios o no; segundo, las relacionadas con los usos de banca por internet y banca móvil en el modelo aditivo para personas bancarizadas; $y$, tercero, las asociadas a la interacción entre servicio móvil y servicios bancarios como un complemento o sustituto en términos de disposición del uso de la banca móvil, servicio y el precio que las personas están dispuestas a pagar.

Finalmente, algunas preguntas se relacionaron con las condiciones socioeconómicas de los usuarios, para tener una idea de las similitudes o diferencias entre ellos, ya que la muestra se seleccionó de forma aleatoria.

\section{El Análisis de Regresión}

El siguiente análisis se da sobre el modelo logístico seleccionado, para estimar la relación entre las disposiciones para utilizar los servicios de banca móvil en áreas rurales en la región de Lima. El modelo logístico fue seleccionado en términos de la naturaleza del cuestionario sobre el servicio de banca móvil, como un modelo transformacional de servicio bancario en un momento en que todavía no está disponible para realizar transacciones, con solo algunas consultas para las cuentas bancarias.

Esta situación específica determinó que la pregunta principal de investigación tenga relación con la voluntad de usar el servicio de banca móvil en lugar de utilizar el servicio bancario tradicional, incluso en una población muy conservadora.

El modelo logístico fue seleccionado por sus características para proporcionar un mejor ajuste para las predicciones en términos de probabilidad, empleando el estimador estadístico de máxima verosimilitud para la estimación de parámetros similares a los cuadrados mínimos generalizados.

\section{LA ESPECIFICACIÓN DEL MODELO}

El modelo se basa en la especificación de las preguntas que persiguen un objetivo definido, que es determinar la disposición para usar el servicio de banca móvil. Esta encuesta se aplicó a un grupo específico de la asociación agrícola en el valle de Huaral, beneficiaria del proyecto FITEL, en colaboración con el Centro Peruano de Estudios Sociales (CEPES), que es una ONG para la instalación de acceso a internet con el fin de crear un sistema para apoyar con información de mercado, siguiendo el modelo aplicado en Kerala.

\section{Modelo 1. Disposición para Utilizar la Banca Móvil}

La primera especificación se definió como la variable endógena, con esta pregunta: "¿Realizaría cualquier transacción o compra usando su teléfono móvil sin el requisito de tener una cuenta bancaria?". Como se requiere una respuesta cualitativa (sí o no), el proceso para realizar la regresión utilizará máxima verosimilitud, específicamente una regresión logística, que se obtuvo con el programa IBM SPSS 
Tabla 3. Variables estimadas en la ecuación de regresión ${ }^{c}$

\begin{tabular}{|c|c|c|c|c|c|c|c|}
\hline & & B & S.E. & Wald & df & Sig. & $\operatorname{Exp}(B)$ \\
\hline \multirow[t]{2}{*}{ Step $1^{a}$} & $\begin{array}{l}\text { @10.¿Considera importante el uso } \\
\text { de Internet para realizar transa }\end{array}$ & $-1,762$ & 604 & 8,506 & 1 &, 004 & 172 \\
\hline & Constant & 5,925 & 1,460 & 16,480 & 1 & ,000 & 374,319 \\
\hline \multirow[t]{3}{*}{ Step $2^{\mathrm{b}}$} & $\begin{array}{l}@ 10 . ¿ \text { Considera importante el uso } \\
\text { de Internet para realizar transa }\end{array}$ & $-1,925$ &, 740 & 6,770 & 1 & ,009 & , 146 \\
\hline & $\begin{array}{l}\text { @13.Utiliza el servicio de mensajes } \\
\text { de texto de su teléfono móvil }\end{array}$ & 19,482 & 5071,739 & ,000 & 1 & 997 & 289148324,993 \\
\hline & Constant & 5,383 & 1,699 & 10,039 & 1 & ,002 & 217,706 \\
\hline
\end{tabular}

a. Variables ingresadas en el paso 1: Q10 ¿Considera importante el uso de Internet para realizar una transacción?

b. Variables ingresadas en el paso 2: Q13: Utiliza el servicio de mensajes de texto de su teléfono móvil

c. El procedimiento Stepwise se detuvo porque la remoción de la variable de menor significancia conduce a un modelo previamente ajustado.

El modelo empleó todas las variables respaldadas por las preguntas en la encuesta, y, luego de una serie de iteraciones, seleccionó las variables más importantes siguiendo el procedimiento forward stepwise (Wald).

El modelo seleccionado es $Y=f\left(X_{10}, X_{13}\right)$. La interpretación de los resultados arroja 84 de 98 casos de personas que dijeron estar dispuestas a usar la banca móvil sin tener que ir al banco o contar con una cuenta bancaria. El porcentaje de una buena predicción es $98,8 \%$ en este modelo. Esto significa que el modelo puede predecir con una precisión del 98,8\% la disposición a usar la banca móvil utilizando dos variables: el hecho de que las personas usen banca por internet y los mensajes de texto. Finalmente, después de una selección por un proceso iterativo, el mejor modelo permanece con la variable Q10, que es: "¿Cree que internet es importante para la banca?, y Q13: "¿Utiliza el servicio de mensajes de texto SMS en su teléfono móvil?".

\section{Modelo 2. Disposición a Pagar por el Servicio de Banca Móvil}

Se realizó otro análisis para determinar la disposición a pagar por el servicio de banca móvil. Este segundo modelo se especificó para una respuesta cuantitativa. El procedimiento empleó MCO.

La variable endógena se definió en la pregunta 18 de la encuesta: "¿Cuánto está dispuesto a pagar mensualmente por la transacción de mobile banking?". El modelo de regresión consideró la misma metodología por iteraciones del modelo original, con todas las preguntas de la encuesta y el programa seleccionado usando la metodología Adelante. El mejor modelo se selecciona con variables significativas para explicar la disposición a pagar; Q21: “¿Cuál es el material más predominante en su casa?”; Q25: “¿Cuál es su nivel de educación?”; y Q30: “¿Cuál es su ingreso promedio mensual?".
Tabla 4. Variables ingresadas y retiradas ${ }^{a}$

\begin{tabular}{|c|c|c|c|}
\hline Model & $\begin{array}{l}\text { Variables } \\
\text { Entered }\end{array}$ & $\begin{array}{l}\text { Variables } \\
\text { Removed }\end{array}$ & Method \\
\hline 1 & $\begin{array}{r}\text { 21. ¿Cuál es } \\
\text { el material } \\
\text { predominante de } \\
\text { la bodega? }\end{array}$ & & $\begin{array}{r}\text { Forward (Criterion: } \\
\text { Probability-of-F-to-enter } \\
<=.050)\end{array}$ \\
\hline 2 & 25. Educación & & $\begin{array}{r}\text { Forward (Criterion: } \\
\text { Probability-of-F-to-enter } \\
<=.050)\end{array}$ \\
\hline 3 & $\begin{array}{r}\text { 30. ¿Cuál es su } \\
\text { ingreso mensual } \\
\text { promedio? }\end{array}$ & & $\begin{array}{r}\text { Forward (Criterion: } \\
\text { Probability-of-F-to-enter } \\
<=.050)\end{array}$ \\
\hline
\end{tabular}

a. Dependent Variable: 18. ¿Cuál es el precio que usted está dispuesto a pagar por mes para realizar transacciones de dinero a través de su teléfono móvil, en caso que necesite hacerla?

\section{Tabla 5. Resumen del modelo ${ }^{c}$}

\begin{tabular}{|c|r|r|r|r|}
\hline Model & \multicolumn{1}{|c|}{ R } & R Square & $\begin{array}{c}\text { Adjusted R } \\
\text { Square }\end{array}$ & $\begin{array}{c}\text { Std. Error of the } \\
\text { Estimate }\end{array}$ \\
\hline 1 & $.286^{\mathrm{a}}$ &, 082 &, 072 & 8,035 \\
\hline 2 & $.348^{\mathrm{b}}$ &, 121 &, 102 & 7,904 \\
\hline 3 & $.398^{\mathrm{c}}$ &, 158 &, 131 & 7,776 \\
\hline
\end{tabular}

a. Predictoras: (Constante), 21.¿Cuál es el material predominante de la bodega?

b. Predictoras: (Constante), 21. ¿Cuál es el material predominante de la bodega?, 25. Educación

c. Predictoras: (Constante), 21. ¿Cuál es el material predominante de la bodega?, 25. Educación, 30. ¿Cuál es su ingreso mensual promedio? 
Tabla 6. Tabla ANOVA ${ }^{\mathrm{d}}$

\begin{tabular}{|r|r|r|r|r|r|r|}
\hline Model & & $\begin{array}{c}\text { Sum of } \\
\text { Squares }\end{array}$ & df & $\begin{array}{c}\text { Mean } \\
\text { Square }\end{array}$ & F & Sig. \\
\hline 1 & Regression & 548,062 & 1 & 548,062 & 8,488 & $.004^{\mathrm{a}}$ \\
\hline & Residual & 6133,876 & 95 & 64,567 & & \\
\hline 2 & Total & 6681,938 & 96 & & & \\
\hline & Regression & 809,501 & 2 & 404,751 & 6,479 & $.002^{\mathrm{b}}$ \\
\hline & Residual & 5872,437 & 94 & 62,473 & & \\
\hline & Total & 6681,938 & 96 & & & \\
\hline & Regression & 1058,802 & 3 & 352,934 & 5,837 & $.001^{\mathrm{c}}$ \\
\hline & Residual & 5623,136 & 93 & 60,464 & & \\
\hline
\end{tabular}

a. Predictoras: (Constante), 21. ¿Cuál es el material predominante de la bodega?

b. Predictoras: (Constante), 21. ¿Cuál es el material predominante de la bodega?, 25. Educación

c. Predictoras: (Constante), 21. ¿Cuál es el material predominante de la bodega?, 25. Educación, 30. ¿Cuál es su ingreso mensual promedio?

d. Variable dependiente: 18. ¿Cuál es el precio que usted está dispuesto a pagar por mes para realizar transacciones de dinero a través de su teléfono móvil, en caso que necesite hacerla?

\section{Tabla 7. Coeficientes ${ }^{a}$}

\begin{tabular}{|l|r|r|r|r|r|}
\hline & & & \\
\end{tabular}

a. Variable dependiente: 18. ¿Cuál es el precio que usted está dispuesto a pagar por mes para realizar transacciones de dinero a través de su teléfono móvil, en caso que necesite hacerla?

La interpretación de los resultados de esta regresión logística proviene del último modelo de iteración, que estima lo siguiente:

$$
Y_{18}=\beta_{0}+\beta_{1} X_{21}+\beta_{2} X_{25}+\beta_{3} X_{30}
$$

Donde:
$Y_{18}:$ pregunta 18; $X_{21}:$ pregunta 21; $X_{25}$ : pregunta 25; $\mathrm{X}_{30}$ : pregunta 30. Los coeficientes para este modelo son $\beta_{o}=14,820 ; \beta_{1}=0,724 ; \beta_{2}=-3,700 ; \beta_{3}=0,001$ Interpretación:

$\beta_{0}=14,82$ soles es el estándar que las personas quieren pagar, si tienen una educación baja y no cuentan con ningún ingreso, y si su casa está construida con materiales baratos. $\beta_{1}$ dice que, si la casa está construida con materiales costosos, están dispuestos a pagar S/ 0,7 más. Las condiciones de la casa de la gente que determinan el nivel de riqueza como un indicador cuando se construye con materiales de primera calidad como cemento y ladrillos dan la estimación de $\mathrm{S} /$ 0,72 o US $\$$ 0,20 de pago mensual para el servicio de banca móvil. $\beta_{2}$ es el nivel de educación de las personas. Se puede predecir que esperan un descuento de S/ 3,7 o de US $\$ 1.5$ mensuales por servicio de banca móvil. $\beta_{3}$ es el nivel de ingreso promedio mensual. Se puede predecir que, por cada S/ 1000 que las personas están ganando, están dispuestos a gastar solo un dólar en banca móvil.

Otro modelo alternativo es el uso de la metodología stepwise, seleccionando el mejor modelo por iteraciones de la siguiente manera:

Tabla 8. Regresión utilizando la metodología stepwise

\begin{tabular}{|c|c|c|c|}
\hline Model & $\begin{array}{c}\text { Variables } \\
\text { Entered }\end{array}$ & $\begin{array}{l}\text { Variables } \\
\text { Removed }\end{array}$ & Method \\
\hline 1 & $\begin{array}{r}\text { 21. ¿Cuál es } \\
\text { el material } \\
\text { predominante } \\
\text { de la bodega? }\end{array}$ & & $\begin{array}{r}\text { Stepwise (Criteria: } \\
\text { Probability-of-F-to-enter <= } \\
\text {.050, Probability-of-F-to- } \\
\text { remove }>=.100 \text { ). }\end{array}$ \\
\hline 2 & 25. Educación & & $\begin{array}{r}\text { Stepwise (Criteria: } \\
\text { Probability-of-F-to-enter <= } \\
.050 \text {, Probability-of-F-to- } \\
\text { remove }>=.100 \text { ). }\end{array}$ \\
\hline 3 & $\begin{array}{r}\text { 30. ¿Cuál es } \\
\text { su ingreso } \\
\text { mensual } \\
\text { promedio? }\end{array}$ & & $\begin{array}{r}\text { Stepwise (Criteria: } \\
\text { Probability-of-F-to-enter <= } \\
.050, \text { Probability-of-F-to- } \\
\text { remove }>=.100 \text { ). }\end{array}$ \\
\hline 4 & & $\begin{array}{r}\text { 21. ¿Cuál es } \\
\text { el material } \\
\text { predominante } \\
\text { de la bodega? }\end{array}$ & $\begin{array}{r}\text { Stepwise (Criteria: } \\
\text { Probability-of-F-to-enter <= } \\
\text {.050, Probability-of-F-to- } \\
\text { remove }>=.100 \text { ). }\end{array}$ \\
\hline 5 & $\begin{array}{r}\text { 12. ¿Puede } \\
\text { navegar } \\
\text { por Internet } \\
\text { utilizando su } \\
\text { teléfono móvil? }\end{array}$ & & $\begin{array}{r}\text { Stepwise (Criteria: } \\
\text { Probability-of-F-to-enter <= } \\
.050 \text {, Probability-of-F-to- } \\
\text { remove }>=.100 \text { ). }\end{array}$ \\
\hline 6 & $\begin{array}{r}\text { 16. ¿Si pudiera } \\
\text { realizar } \\
\text { consultaso } \\
\text { transacciones } \\
\text { bancarias a } \\
\text { través de su } \\
\text { teléfono móvil, } \\
\text { las haría? }\end{array}$ & & $\begin{array}{r}\text { Stepwise (Criteria: } \\
\text { Probability-of-F-to-enter <- } \\
\text {.050, Probability-of-F-to- } \\
\text { remove }>=.100 \text { ). }\end{array}$ \\
\hline
\end{tabular}

a. Variable dependiente: 18. ¿Cuál es el precio que usted está dispuesto a pagar por mes para realizar transacciones de dinero a través de su teléfono móvil, en caso que necesite hacerla? 
Tabla 9. Resumen del modelo

\begin{tabular}{|c|c|r|r|r|}
\hline Model & \multicolumn{1}{|c|}{$\mathrm{R}$} & R Square & \multicolumn{1}{|c|}{$\begin{array}{c}\text { Adjusted R } \\
\text { Square }\end{array}$} & $\begin{array}{c}\text { Std. Error of the } \\
\text { Estimate }\end{array}$ \\
\hline 1 & $.286^{\mathrm{a}}$ &, 082 &, 072 & 8,035 \\
\hline 2 & $.348^{\mathrm{b}}$ &, 121 &, 102 & 7,904 \\
\hline 3 & $.398^{\mathrm{c}}$ &, 158 &, 131 & 7,776 \\
\hline 4 & $.365^{\mathrm{d}}$ &, 134 &, 115 & 7,848 \\
\hline 5 & $.421^{\mathrm{e}}$ &, 178 &, 151 & 7,687 \\
\hline 6 & $.461^{\mathrm{f}}$ &, 212 &, 178 & 7,564 \\
\hline
\end{tabular}

a. Predictoras: (Constante), 21. ¿Cuál es el material predominante de la bodega?

b. Predictoras: (Constante), 21. ¿Cuál es el material predominante de la bodega?, 25. Educación

c. Predictoras: (Constante), 21. ¿Cuál es el material predominante de la bodega?, 25. Educación, 30. ¿Cuál es su ingreso mensual promedio?

d. Predictoras: (Constante), 25. Educación, 30. ¿Cuál es su ingreso mensual promedio?

e. Predictoras: (Constante), 25. Educación, 30. ¿Cuál es su ingreso mensual promedio?, 12. ¿Puede navegar por Internet utilizando su teléfono móvil?

f. Predictoras: (Constante), 25. Educación, 30. ¿Cuál es su ingreso mensual promedio?, 12. ¿Puede navegar por Internet utilizando su teléfono móvil?, 16. ¿Si pudiera realizar consultas o transacciones bancarias a través de su teléfono móvil, las haría?

Después de seis iteraciones, el programa seleccionó el mejor modelo considerando la pregunta 25, relacionada con el nivel de educación; la pregunta 30, relacionada con el ingreso promedio mensual; la pregunta 12, que inquiere si es posible obtener acceso a internet usando el teléfono móvil; y la pregunta 16, sobre la percepción de la banca móvil.

Es importante que el coeficiente de regresión sea de 21\% en el modelo seleccionado, lo que significa que el modelo estima el 21\% de las predicciones de las variaciones de la variable endógena, que es la cantidad que las personas están dispuestas a pagar por la banca móvil.

\section{Tabla 10. Tabla ANOVA ${ }^{\mathrm{g}}$}

\begin{tabular}{|c|c|c|c|c|c|c|}
\hline & Model & $\begin{array}{l}\text { Sum of } \\
\text { Squares }\end{array}$ & df & $\begin{array}{l}\text { Mean } \\
\text { Square }\end{array}$ & F & Sig. \\
\hline \multirow{3}{*}{1} & Regression & 548,062 & 1 & 548,062 & 8,488 & $.004^{\mathrm{a}}$ \\
\hline & Residual & 6133,876 & 95 & 64,567 & & \\
\hline & Total & 6681,938 & 96 & & & \\
\hline \multirow{3}{*}{2} & Regression & 809,501 & 2 & 404,751 & 6,479 & $.002^{b}$ \\
\hline & Residual & 5872,437 & 94 & 62,473 & & \\
\hline & Total & 6681,938 & 96 & & & \\
\hline \multirow{3}{*}{3} & Regression & 1058,802 & 3 & 352,934 & 5,837 & $.001^{c}$ \\
\hline & Residual & 5623,136 & 93 & 60,464 & & \\
\hline & Total & 6681,938 & 96 & & & \\
\hline \multirow{3}{*}{4} & Regression & 892,447 & 2 & 446,223 & 7,245 & $.001^{d}$ \\
\hline & Residual & 5789,492 & 94 & 61,590 & & \\
\hline & Total & 6681,938 & 96 & & & \\
\hline \multirow{3}{*}{5} & Regression & 1186,582 & 3 & 395,527 & 6,694 & $.000^{\circ}$ \\
\hline & Residual & 5495,356 & 93 & 59,090 & & \\
\hline & Total & 6681,938 & 96 & & & \\
\hline \multirow{3}{*}{6} & Regression & 1418,854 & 4 & 354,713 & 6,200 & $.000^{\mathrm{f}}$ \\
\hline & Residual & 5263,085 & 92 & 57,207 & & \\
\hline & Total & 6681,938 & 96 & & & \\
\hline
\end{tabular}

a. Predictoras: (Constante), 21. ¿Cuál es el material predominante de la bodega?

b. Predictoras: (Constante), 21. ¿Cuál es el material predominante de la bodega?, 25. Educación

c. Predictoras: (Constante), 21. ¿Cuál es el material predominante de la bodega?, 25. Educación, 30. ¿Cuál es su ingreso mensual promedio?

d. Predictoras: (Constante), 25. Educación, 30. ¿Cuál es su ingreso mensual promedio?

e. Predictoras: (Constante), 25. Educación, 30. ¿Cuál es su ingreso mensual promedio?, 12. ¿Puede navegar por Internet utilizando su teléfono móvil?

f. Predictoras: (Constante), 25. Educación, 30. ¿Cuál es su ingreso mensual promedio?, 12. ¿Puede navegar por Internet utilizando su teléfono móvil?, 16. ¿Si pudiera realizar consultas o transacciones bancarias a través de su teléfono móvil, las haría?

g. Variable dependiente: 18. ¿Cuál es el precio que usted está dispuesto a pagar por mes para realizar transacciones de dinero a través de su teléfono móvil, en caso que necesite hacerla?

\section{Tabla 11. Coeficientes del modeloa}

\begin{tabular}{|c|c|c|c|c|c|c|}
\hline & \multirow{2}{*}{ Model } & \multicolumn{2}{|c|}{$\begin{array}{l}\text { Unstandardized } \\
\text { Coefficients }\end{array}$} & \multirow{2}{*}{$\begin{array}{c}\text { Standardized } \\
\text { Coefficients } \\
\text { Beta }\end{array}$} & \multirow{2}{*}{$\mathrm{t}$} & \multirow{2}{*}{ Sig. } \\
\hline & & B & Std. Error & & & \\
\hline 1 & (Constant) & -984 & 1,464 & & -673 &, 503 \\
\hline & 21. ¿Cuál es el material predominante de la bodega? & 1,189 &, 408 & ,286 & 2,913 &, 004 \\
\hline \multirow[t]{3}{*}{2} & (Constant) & 11,736 & 6,383 & & 1,839 & .069 \\
\hline & 21. ¿Cuál es el material predominante de la bodega? & 1,088 &, 404 & ,262 & 2,691 &, 008 \\
\hline & 25. Educación & $-2,903$ & 1,419 & -199 & $-2,046$ & 044 \\
\hline \multirow[t]{4}{*}{3} & (Constant) & 14,820 & 6,460 & & 2,294 & 024 \\
\hline & 21. ¿Cuál es el material predominante de la bodega? &, 724 & .436 & ,174 & 1,659 & ,101 \\
\hline & 25. Educación & $-3,700$ & 1,450 &,- 254 & $-2,551$ &, 012 \\
\hline & 30. ¿Cuál es su ingreso mensual promedio? & 001 &, 000 & 216 & 2,031 &, 045 \\
\hline \multirow[t]{3}{*}{4} & (Constant) & 18,746 & 6,067 & & 3,090 & ,003 \\
\hline & 25. Educación & $-4,225$ & 1,429 & -290 & $-2,957$ &, 004 \\
\hline & 30. ¿Cuál es su ingreso mensual promedio? & 001 &, 000 & 289 & 2,948 & ,004 \\
\hline
\end{tabular}


Tabla 11. Coeficientes del modelo ${ }^{a}$ (cont.)

\begin{tabular}{|c|c|c|c|c|c|c|}
\hline & \multirow{2}{*}{ Model } & \multicolumn{2}{|c|}{$\begin{array}{c}\text { Unstandardized } \\
\text { Coefficients }\end{array}$} & \multirow{2}{*}{$\begin{array}{c}\text { Standardized } \\
\text { Coefficients } \\
\text { Beta }\end{array}$} & \multirow{2}{*}{$\mathrm{t}$} & \multirow{2}{*}{ Sig. } \\
\hline & & B & Std. Error & & & \\
\hline \multirow[t]{4}{*}{5} & (Constant) & 18,790 & 5,942 & & 3,162 &, 002 \\
\hline & 25. Educación & $-3,537$ & 1,433 & -243 & $-2,468$ & 015 \\
\hline & 30. Cuál es su ingreso mensual promedio? & 001 & ,000 & ,283 & 2,945 &, 004 \\
\hline & 12. Puede navegar por Internet utilizando su teléfono móvil? & $-4,026$ & 1,805 &,- 215 & $-2,231$ & 028 \\
\hline \multirow[t]{5}{*}{6} & (Constant) & 15,140 & 6,121 & & 2,473 & 015 \\
\hline & 25. Educación & $-3,458$ & 1,410 & -237 & $-2,452$ & ,016 \\
\hline & 30. Cuál es su ingreso mensual promedio? & 001 & ,000 & ,288 & 3,045 &, 003 \\
\hline & 12. Puede navegar por Internet utilizando su teléfono móvil? & $-5,960$ & 2,018 &,- 318 & $-2,953$ &, 004 \\
\hline & $\begin{array}{l}\text { 16. Si pudiera realizar consultas o transacciones bancarias a } \\
\text { través de su teléfono móvil, las haría? }\end{array}$ & 5,361 & 2,660 & ,213 & 2,015 & 047 \\
\hline
\end{tabular}

a. Variable dependiente: 18. ¿Cuál es el precio que usted está dispuesto a pagar por mes para realizar transacciones de dinero a través de su teléfono móvil, en caso que necesite hacerla?

Finalmente, los coeficientes de las variables 25, 30, $12 \mathrm{y}$ 16 explican que las personas que viven con un nivel de educación superior esperan tener un descuento al usar el servicio de banca móvil, y las personas con un salario mensual más alto también están dispuestas a pagar, pero en un mínimo proporcional (S/ 0,01 por cada S/ 10 de ingresos). Otra variable explica que, si las personas pueden usar la banca móvil, lo harán en un "modelo aditivo", que significa tener cuentas bancarias.

Otra interpretación que puede relacionarse con el modelo logístico es que, dado que el tamaño del mercado en Huaral es de 164660 habitantes, el del mercado de banca móvil será de 92\%; es decir, de 160708 usuarios potenciales.

El mercado está determinado por la Asociación de Usuarios del Distrito del Valle de Chancay-Huaral, como una organización que representa a los señores de la tierra para la distribución del agua para la población agrícola. El total de la asociación está compuesto por 17 comisiones por una extensión de 22 677,88 hectáreas. La asociación representa a 6152 usuarios. El presente survey se aplicó a una muestra de 98 de ellos. En términos del modelo y la predicción del tamaño de la banca móvil, este mercado será el 98,8\% de los 6152 usuarios, que totalizan 6078 usuarios potenciales.

\section{Entrevistas a Expertos}

Esta sección fue desarrollada siguiendo la opinión de expertos en telecomunicaciones de los sectores público y privado.

Desde el sector público, con Narda Sotomayor, del Regulador de Servicios Bancarios y Seguros en Perú. Por representar a las empresas, desde Telefónica Móviles (TM), la entrevista se enfocó en algunos aspectos importantes desde el punto de vista de la empresa y de los clientes para percibir cómo el agente económico enfrentará el proceso de implementación de banca móvil.

Desde el punto de vista de TM, la posibilidad de ofrecer servicios de banca móvil a los clientes de prepago ofrece una nueva forma de fidelización, que brinda una ventaja competitiva.
Sobre los factores técnicos necesarios para considerar la implementación del servicio de banca móvil basado en mensajes SMS, el factor principal es la seguridad que se puede proveer para este tipo de servicio para ofrecer confiabilidad.

También es posible dar el servicio de banca móvil basado en un navegador de internet que requiere que el teléfono tenga aplicaciones Java. El entrevistador indicó un porcentaje de usuarios entre el $5 \%$ y el 10\% de la población total.

En cuanto al porcentaje de la población que tiene en el plan de prepago una aplicación de transmisión de datos en el teléfono, TM dijo que es del $5 \%$ al $7 \%$ de la población total.

Finalmente, en relación con la disposición del pago o el valor de las transacciones bancarias móviles, TM afirmó que, incluso si no tienen una investigación de mercado al respecto, en general esperan alrededor de US\$ 0,30 por transacción local y de US\$1,7 por transacción de larga distancia.

Estas estimaciones son muy similares a la respuesta en el cuestionario para la pregunta 18, sobre la disposición a pagar por transacción utilizando la banca móvil.

Con relación al regulador del sector bancario en el Perú, las principales ventajas para implementar la banca móvil son las siguientes:

- Reducción de los costos de transacción, especialmente para áreas remotas cuando las personas no bancarizadas pueden usarla para transacciones comerciales y remesas.

- Reducción del costo social en el tiempo gastado para ir a los bancos.

- Proporcionar recursos para actividades productivas de finanzas.

- Reducir el riesgo al no cargar dinero en efectivo.

Para la banca móvil, en términos de instrumento de financiación, se requiere de un regulador para respaldar las transacciones con cuentas bancarias como un modelo aditivo, que también brinde la posibilidad de crear redes de distribución más eficientes para un segmento de bajos ingresos, que ahora no puede usar el sistema bancario. 


\section{CONCLUSIONES Y RECOMENDACIONES}

\section{Conclusiones}

Los principales hallazgos en esta investigación están relacionados con el factor que explica la disposición o no disposición del uso del servicio de banca móvil, que es el hecho de que las personas responden que usarán los servicios de banca móvil si tienen la posibilidad de emplear banca por internet.

Este hecho se explica por los siguientes factores:

- La gente considera que la seguridad es un factor muy importante, y, dado que saben cómo usar la banca por internet, parece ser la forma más segura de utilizar la banca móvil en un mercado donde los mensajes de texto SMS apenas comienzan a usarse como una forma de obtener información sobre cuentas bancarias.

- Es importante darse cuenta de que el elemento más importante en esta encuesta e investigación es el hecho de que el servicio de banca móvil aún no está disponible. En este caso, la presente investigación puede usarse como referencia para establecer una línea de base. El servicio se lanzará con el propósito de estudiar sus efectos futuros en términos de desarrollo.

La tecnología móvil ha demostrado que puede tener efectos transformadores en una sociedad, ya que, desde que el modelo FITEL se implementó en 1998, los pobres de las zonas rurales han identificado el valor económico del servicio móvil.

La experiencia con la política de acceso universal en el Perú ha demostrado que, cuando las personas conocen un servicio como el de telefonía pública y establecen la red social, los beneficios económicos en términos de costos de transporte y tiempo son lo suficientemente fuertes como para usarlo.

Después de un tiempo, cuando el mercado es lo suficientemente grande, los operadores móviles ofrecen sus servicios expandiendo su red y, nuevamente, los usuarios perciben claramente los beneficios de la movilidad y la ubicuidad. Una de las razones de que la política de acceso universal del Estado no considere ofrecer incentivos en términos de implementación de proyectos móviles es que la dinámica del servicio móvil va de la mano del mercado y extiende el uso de dispositivos móviles entre los pobres en economías emergentes. Con relación a la banca móvil, considera la tecnología para expandir el sistema bancario a los pobres. Por lo tanto, en el caso peruano es importante conocer la forma de utilizar las instalaciones del teléfono móvil para acercar a las personas al sistema bancario.

El Gobierno del Perú ha presentado propuestas regulatorias para la banca móvil y facilita las iniciativas de los intermediarios financieros, que actualmente ofrecen sus servicios a través de POS o internet. El objetivo es crear un impacto transformador para brindar nuevos productos o servicios y canales, para proporcionar el servicio financiero que no se incluyeron antes debido a la inaccesibilidad geográfica o a la distancia de los principales mercados o ciudades.

En el caso del Perú, el 28\% de las personas acceden al sistema bancario, en promedio, en términos de deudores/ población, y el 44\% en términos de depósitos/población, siguiendo la idea de utilizar el teléfono móvil como un nuevo canal para acceder al servicio financiero con los siguientes efectos: i) reducir los costos de transacción, especialmente en áreas remotas para transacciones, incluyendo remesas; ii) darles más tiempo a las actividades productivas, especialmente en las zonas rurales; iii) proporcionar asistencia financiera para actividades generadoras de ingresos; y iv) reducir la necesidad de administrar efectivo y sus riesgos implícitos.

La promoción de estas actividades por parte del Estado, como parte de la política económica financiera, se explica por el denominado "dinero electrónico", e implica menos costos para el cliente porque, en principio, el dinero electrónico no se considera dinero y no genera costos por su supervisión. También permite expandir redes para ofrecer el servicio en micromercados, con menores costos que lo hagan más accesible.

Las principales razones por las que los pobres no usan el sistema bancario son estas: i) accesibilidad a la red de agencias bancarias ubicadas en las principales ciudades, ii) calificación de los clientes del sistema bancario en términos de garantías y colaterales para créditos o préstamos, iii) altos costos de operación y tarifas de transacción, y iv) el tiempo que lleva obtener la aprobación para los bancos conlleva un alto costo de oportunidad.

Como se mostró en la presente investigación, el mercado de la telefonía móvil se ha expandido a un ritmo exponencial, llenando el vacío del mercado para el acceso universal. En el caso del Perú, el marco regulatorio para teléfonos móviles en términos de costos y cargos de interconexión se ha otorgado como condición especial para su expansión en un mercado en crecimiento.

En realidad, la cobertura móvil incluye casi el territorio de espera, contando las principales ciudades de la selva amazónica, debido a la tecnología satelital de apoyo cuando es necesario. En este caso, FITEL Projects ayudó a instalar primero las antenas satelitales para telefonía pública, y a expandir el mercado para los futuros teléfonos móviles.

Desde el punto de vista del operador, este tipo de servicio, incluso de manera aditiva (es decir, trabajar en coordinación con los bancos), podría ser una forma interesante de abrir un nuevo campo de servicio para los usuarios de prepago en el caso del modelo de SMS En cuanto al servicio de banca móvil que utiliza el navegador de internet, es más fácil proporcionar la aplicación, y también es interesante para la competencia, al proporcionar más contenidos en tecnologías $3 \mathrm{G}$ para smartphones.

Desde el punto de vista del regulador, la banca móvil es factible, y el marco legal se adaptará para incorporar el servicio para las instituciones de financiamiento intermediario, siguiendo un modelo de alto jardín, y también dando la oportunidad a los operadores móviles de ofrecer el servicio. 
El Estado peruano ya ha presentado para su aprobación al Congreso de la República un marco legal para los servicios de banca móvil utilizando transacciones con dinero electrónico, con el fin de promover la inclusión financiera para las personas no bancarizadas.

En términos del modelo logístico aplicado para la encuesta en Lima, es posible concluir lo siguiente:

- Las personas del valle de Huaral acceden a internet desde que implementaron un sitio web para obtener información relevante del mercado, en términos de oportunidades para hacer negocios y precios. La presente encuesta se centró en este grupo específico con el fin de demostrar que el uso de las TIC podría contribuir a cubrir la brecha entre el mercado y las zonas rurales, la así llamada brecha digital. Esta investigación ha encontrado evidencia estadística de que la Asociación de Agricultura del Valle de Huaral está dispuesta a utilizar y pagar un dólar en promedio mensual para el servicio de banca móvil, ya que este monto representa el costo de oportunidad para no usar banca por internet en lugar de usar banca móvil. También podría considerarse como un modelo transformacional, lo que significa: incluso sin usar bancos o tener cuentas bancarias.

- Esta investigación ha empleado modelos econométricos, de acuerdo con el propósito de la encuesta. Los datos han sido analizados usando dos modelos: i) el primero es un modelo logístico, que encontró la probabilidad de utilizar la banca móvil, al preguntar sobre el servicio. Este modelo ha seleccionado como la variable más importante para explicar esta disposición la que se relacionó con la posibilidad de utilizar la banca móvil, incluso si actualmente no cuentan con el servicio; ii) el segundo es un modelo lineal, estimado mediante MCO, que asoció la disposición a pagar que depende del nivel de educación, el nivel de riqueza en términos de las condiciones de vida de las personas y el nivel de ingresos mensuales; se determinó que la percepción de las personas hoy en día es que, si pudieran usar la banca por internet a través del teléfono móvil, lo harían. Ello significa que es una percepción positiva en términos del modelo TAM, explicado anteriormente.

\section{Recomendaciones}

La política de acceso universal en el sector de las telecomunicaciones ha estado incentivando al sector privado a desplegar sus redes para aumentar la cobertura, llegando a las personas excluidas, de acuerdo con el propósito principal de cubrir la brecha real, principalmente en el caso del Perú. Al utilizar políticas de incentivos, como los proyectos FITEL, el sector de las telecomunicaciones ha desarrollado una columna vertebral nacional de conectividad, para que las personas excluidas puedan lograr una comunicación más integrada con el mundo. En este sentido, la política de acceso universal en el país ha alcanzado sus objetivos principales, y el siguiente paso es proporcionar servicio universal para brindar a los clientes una línea telefónica cuando sea necesario. El desarrollo de la telefonía móvil ha contribuido a acelerar el servicio universal, y, actualmente, la penetración de los teléfonos móviles se está extendiendo a casi todo el Perú.

El siguiente paso debe ser continuar con la inclusión social, mejorando la coordinación entre los sectores económicos en términos de transporte y comunicaciones, energía para apoyar el despliegue de la infraestructura, la salud y la educación, así como los servicios públicos en general. Pero el otro lado de la estrategia para la inclusión social debe considerar la brecha del mercado, que está relacionada no solo con la infraestructura, sino también con la capacidad económica para ser parte del mercado, con suficiente poder adquisitivo.

En ese sentido, la política de banca móvil será uno de los factores más importantes que se deben considerar para la inclusión financiera, especialmente en las áreas rurales. La presente investigación ha demostrado que la actitud de las personas para usar la banca móvil es positiva, pero también se requiere del marco legal y de los incentivos para que los operadores móviles respalden esta iniciativa comercial.

Así, una recomendación podría ser la de organizar foros para discutir el tema con el Gobierno y el sector privado, incluidos los intermediarios financieros que también prestan el servicio por otros medios, pero que están dispuestos a utilizar el sistema de banca móvil.

Para los intermediarios de financiamiento es muy importante este tipo de investigación. En futuras investigaciones, será fundamental considerar otras regiones en el Perú, mediante una encuesta nacional con suficiente muestra para determinar la disposición a usar y pagar los servicios de banca móvil, ya que las investigaciones de mercado todavía no han sido aplicadas.

\section{REFERENCIAS}

Barrantes, R. (2007). Oportunidades móviles: pobreza y acceso a la telefonía en América Latina y el Caribe. El caso de Perú. Lima: Dirsi.

Camner, G., Pulver, C., \& Sjoblom, E. (2009, 16 de marzo). What makes a successful mobile money implementation? Learnings from M-PESA in Kenya and Tanzania. Recuperado de https://www.gsma. com/mobilefordevelopment/programme/mobilemoney/what-makes-a-successful-mobile-moneyimplementation-learnings-from-m-pesa-in-kenyaand-tanzania/

Dahlberg, T. \& Mallat, N. (2002). Mobile payment service development. Managerial implications of consumer value perceptions. Proceedings of the European Conference on Information Systems (ECIS), Poland, 139, 649-657. Recuperado de http://aisel.aisnet.org/cgi/ viewcontent.cgi?article=1144\&context=ecis2002

Donner, J. \& Téllez, C. A. (2008). Mobile banking and economic development: Linking adoption, impact, and use. Asian Journal of Communication, 18(4), 318-322. 
Enríquez, Á., Fernández de Lis, S., López, V. \& Rodríguez, I. (2009). M-Banking: Oportunidades y barreras para el desarrollo de servicios financieros a través de tecnologías móviles en América Latina y el Caribe. Washington, DC: Banco Interamericano de Desarrollo. Recuperado de https://publications.iadb.org/ handle/11319/6163

Failache, C. (Noviembre, 2016). La Teoría del Desarrollo Económico de Adam Smith. [Notas para el curso Teorías del Desarrollo Económico]. Facultad de Ciencias Económicas y de Administración, Universidad de la República.

Galperin, H. (2005). Wireless networks and rural development: Opportunities for Latin America. Information Technologies and International Development, 2(3), 47-56.

Galperin, H. \& Mariscal, J. (2007). Digital Poverty: Latin American and Caribbean Perspectives. United Kingdom: Intermediate Technology Publications

Hughes, N. \& Lonie, S. (2007). M-PESA: Mobile money for the "unbanked": Turning cellphones into 24-hour tellers in Kenya. Innovations: Technology, Governance, Globalization, 2(1-2), 63-81.

Jyrkönen, H. \& Paunonen, H. (2003). Card, Internet and Mobile Payments in Finland. (Bank of Finland Discussion Paper No. 8). Recuperado de https://papers. ssrn.com/sol3/papers.cfm?abstract_id=444460

Kreyer, N., Pousttchi, K. \& Turowski, K. (2002). Characteristics of mobile payment procedures. En Z. Maamar, W. Mansoor, \& W. J. van den Heuvel (Eds.), Proceedings of the ISMIS 2002 Workshop on $M$-Services. Recuperado de https://mpra.ub.unimuenchen.de/3786/

Lyman, T., Ivatury, G. \& Staschen, S. (2006). Use of agents in branchless banking for the poor: Rewards, risks, and Regulation (CGAP Focus Note No. 38). Washington, DC: World Bank.

Lyman, T., Pickens, M. \& Porteous, D. (2008). Regulating transformational branchless banking: Mobile phones and other technology to increase access to finance. (CGAP Focus Note No. 43). Washington, DC: World Bank.

Mallat, N. (2007). Exploring consumer adoption of mobile payments - A qualitative study. The Journal of Strategic Information Systems, 16(4), 413-432. doi:10.1016/j. jsis.2007.08.001

Mallat, N., Rossi, M. \& Tuunainen, V. C. (2004). Mobile banking services. Communications of the ACM, 47(5), 42-46.

Mas, I. \& Rotman, S. (2008). Going Cashless at the Point of Sale: Hits and Misses in Developed Countries. (CGAP Focus Note No. 51). Washington, DC: World Bank.

Mas, I. \& Kumar, K. (2008). Banking on Mobiles: Why, How, for Whom? (CGAP Focus Note No. 48). Washington, DC: World Bank.
Mas, I. \& Rosenberg, J. (2009, 15 de mayo). The role of mobile operators in expanding access to finance. Recuperado de https://www.cgap.org/sites/default/ files/CGAP-Brief-The-Role-of-Mobile-Operators-inExpanding-Access-to-Finance-May-2009.pdf

Navas-Sabater, J., Dymond, A. \&, Juntunen, N. (2002). Telecommunications and Information Services for the Poor. Toward a Strategy for Universal Access (World Bank Discussion Paper No. 432). Washington, DC: World Bank

Liebert, M., Chung, N. \& Kwon, S. (2009). The effects of customers' mobile experience and technical support on the intention to use mobile banking CyberPsychology \& Behavior, 12(5), 539-543. doi: 10.1089/cpb.2009.0014

López, R. \& Valdés, A. (2000). Fighting rural poverty in Latin America: New evidence of the effects of education, demographics, and access to land. Economic Development and Cultural Change, 49(1), 197-211.

Lusthaus, C., Adrien, M. H., Anderson, G., Carden, F., \& Montalván, G. P. (2002). Organizational Assessment: A Framework for Improving Performance. Washington, DC: Banco Interamericano de Desarrollo.

Mariscal, J. (2009). Mobiles for Development: M-Banking. México: CIDE.

Ondrus, J. \& Pigneur, Y. (2006). Towards a holistic analysis of mobile payments: A multiple perspectives approach Electronic Commerce Research and Applications, 5(2), 246-257.

Rosenberg, J. (2008). Lessons from M-PESA - A Conversation with Nick Hughes, Vodafone Head of International Mobile Payment Solutions. [Webcast]. Recuperado de mms://wbmswebcast1.worldbank.org/ CGAP/10675199/BBLTechnologyTeam_20081029.wmv

Rosenberg, J. (2008). Lecciones de M-PESA: una conversación con Nick Hughes, Director de Vodafone de Soluciones de Pagos Móviles Internacionales. Disponible en https: //wbmswebcast1.worldbank.org/ CGAP/10675199/BBLTechnologyTeam_20081029.wmv

Rosenberg, J. (2009). An M-PESA pioneer: Nick Hughes. Recuperado de http://technology.cgap. org/2009/06/10/an-m-pesa-pioneer-nick-hughes

Rosenberg, J. \& Morawczynski, O. (2008, 17 de junio). Why has M-PESA become so popular in Kenya? [Publicación web] Recuperado de http://www.cgap.org/blog/whyhas-m-pesa-become-sopopular-kenya

Van Bossuyt, M. \& Van Hove, L. (2007). Mobile payment models and their implications for NextGen MSPs. Digital Policy, Regulation and Governance, 9(5), 31-43. doi:10.1108/14636690710816435 